\title{
Combination of Correctors Rescues CFTR Transmembrane-Domain Mutants by Mitigating their Interactions with Proteostasis
}

\author{
Miquéias Lopes-Pacheco Clément Boinot Inna Sabirzhanova \\ Daniele Rapino Liudmila Cebotaru
}

Departments of Physiology and Medicine, Johns Hopkins University, Baltimore, USA

\section{Key Words}

CFTR mutants $•$ Cystic fibrosis $•$ Electrophysiology $•$ Heat shock protein $\bullet$ Intracellular trafficking - Membrane-spanning • Precision medicine $\bullet$ Protein folding • Proteostasis network

\begin{abstract}
Background/Aims: Premature degradation of mutated cystic fibrosis transmembrane conductance regulator (CFTR) protein causes cystic fibrosis (CF), the commonest Mendelian disease in Caucasians. Despite recent advances in precision medicines for CF patients, many CFTR mutants have not been characterized and the effects of these new therapeutic approaches are still unclear for those mutants. Methods: Cells transfected or stably expressing four CFTR transmembrane-domain mutants (G85E, E92K, L1077P, and M1101K) were used to: 1) characterize the mutants according to their protein expression, thermal sensitivity, and degradation pathways; 2) evaluate the effects of correctors in rescuing them; and 3) explore the effects of correctors on CFTR interactions with proteostasis components. Results: All four mutants exhibited lower protein expression than did wild type-CFTR, and they were degraded by proteasomes and aggresomes. At low temperature, only cells expressing the mutants L1077P and M1101K exhibited increased CFTR maturation. Co-administration of C4 and C18 showed the greatest effect, restoring functional expression and partial stability of CFTR bearing E92K, L1077P, or M1101K at the cell surface. However, this treatment was inefficient in rectifying the defect of CFTR bearing G85E. Correctors rescued CFTR mutants by reducing their interactions with proteostasis components associated with protein retention in the endoplasmic reticulum and ubiquitination. Conclusion: Co-administration of C4 and C18 rescued CFTR transmembrane-domain mutants by remodeling the CFTR interactome.
\end{abstract}

\section{Introduction}

Misfolded proteins cause human diseases as a result of their engagement with protein homeostasis (proteostasis) networks that assess the proteins' poor quality and target them for degradation $[1,2]$. In cystic fibrosis (CF), mutations in the CF transmembrane 


\section{Cellular Physiology Cell Physiol Biochem 2017;41:2194-2210 \begin{tabular}{ll|l} 
and Biochemistry $10.1159 / 000475578$ & Published online: April 24, 2017 & $\begin{array}{l}\text { () } 2017 \text { The Author(s). } \\
\text { www.karger.com/cpb }\end{array}$
\end{tabular} \\ Lopes-Pacheco et al.: Correctors Rescue CFTR Transmembrane-Domain Mutants}

conductance regulator (CFTR) gene often lead to misfolded CFTR protein that malfunctions [3]. CFTR encodes a chloride channel located at the apical membrane of several epithelial tissues, and its loss of activity impairs the ionic and fluid transcellular balance, resulting in dehydration of the epithelial lining and triggering the progressive pathological cascade of the disease. The major cause of CF morbidity and mortality is the pulmonary disorder caused by an accumulation of thick and tenacious mucus, inflammation, and recurrent infections that impair lung function and end in respiratory failure [4].

CFTR (also known as ABCC7) is a member of ATP-binding cassette family and is composed of five domains: two nucleotide-binding domains (NBD1/2) and one regulatory domain that control channel activity, and two transmembrane domains (TMD1/2) that form the pore for chloride conductance. Each TMD contains six hydrophobic $\alpha$-helices that form the membrane-spanning segments (MS1-6 and MS7-12). They are connected by three extracellular and two intracellular loops (ICL1/2 and ICL3/4). Appropriate interactions between TMDs and NBDs are critical for the mature protein folding and functioning of CFTR $[5,6]$.

During CFTR translation, multiple chaperones/co-chaperones orchestrate the protein's folding at the endoplasmic reticulum (ER); folding is followed by glycosylation in the Golgi apparatus and trafficking to the cell surface $[1,2]$. The most prevalent CFTR mutant is a deletion of phenylalanine at position $508(\Delta \mathrm{F} 508)$ that reduces the thermal stability of NBD1 and affects CFTR's interdomain interactions. Hence, misfolded $\triangle$ F508-CFTR is arrested and targeted for ER-associated degradation (ERAD) by the ubiquitin-proteasome pathway [5, 6]. A small portion of $\triangle F 508$-CFTR may evade ERAD and proceed to the plasma membrane; however, a system of peripheral quality control proteins recognizes and quickly removes this misfolded protein for lysosomal elimination [7].

Worldwide, about $80 \%$ of CF patients possess the mutant $\Delta \mathrm{F} 508$, with only half of them homozygous for this mutant and the remainder bearing other (non- $\Delta$ F508) mutants on the second allele $[4,8]$. Nearly 2,000 mutations have been reported in the CF Mutation Database (CFTR1) (see [9]) including the TMD mutants G85E, E92K, L1077P, and M1101K. To date, the impact of these mutations on the overall structure of CFTR has not been well characterized. According to the CFTR2 database (see [9]), G85E is among the 23 commonest mutations globally, whereas E92K, L1077P, and M1101K are rare, but presenting a higher incidence $(>1 \%)$ in some ethnic populations (Turkish, southern Italian, and Hutterites, respectively). All four of these mutants cause severe disease when combined with another mutant-causing $\mathrm{CF}$, and they are located at highly evolutionarily conserved sites: G85E and E92K are found at MS1 in the TMD1, M1101K is located in MS11 in TMD2 [10] whereas L1077P is situated at ICL4 in the TMD2 [11]. A better elucidation of how these mutants affect CFTR processing may suggest ways to rectify their particular molecular defects and develop appropriate treatments for CF patients bearing them.

Over the past few decades, the life expectancy of CF patients has been lengthened, thanks to the early diagnosis and the availability of more effective therapeutic approaches; however, the high costs and burden of the necessary treatments limit patients' quality of life [12]. Two drugs discovered by high-throughput screening (ivacaftor and lumacaftor) have translated the results of bench research into pharmaceutical treatments for CF patients. Ivacaftor (or VX-770) is a potentiator that stimulates CFTR gating in mutants in which the protein is present at the cell surface, but exhibits residual function or no function at all [13]. On the other hand, lumacaftor (or VX-809) is a corrector that restores the processing and trafficking of the mutated CFTR to the plasma membrane by increasing its folding efficacy [14]. Individual administration of either of these molecules has been unsuccessful in improving lung function in $\Delta \mathrm{F} 508$-homozygous patients $[15,16]$, but the co-administration of lumacaftor/ivacaftor has shown clinical benefit in these patients $[17,18]$. To date, the European Medicines Agency and the U.S. Food and Drug Administration have licensed the use of ivacaftor (Kalydeco ${ }^{\mathrm{TM}}$ ) for CF patients who bear one of 10 CFTR mutations causing faulty conductance, and the combination lumacaftor/ivacaftor (Orkambi ${ }^{\mathrm{TM}}$ ) for $\Delta \mathrm{F} 508$ homozygous CF patients. Despite these breakthroughs in personalizing CF treatments, 


\section{Cellular Physiology Cell Physiol Biochem 2017;41:2194-2210

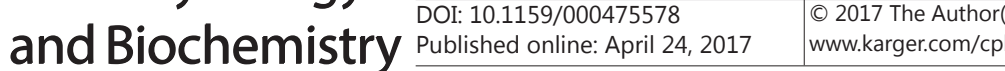

Lopes-Pacheco et al.: Correctors Rescue CFTR Transmembrane-Domain Mutants

for thousands of patients $(\Delta \mathrm{F} 508$-heterozygotes or those bearing a wide range of orphan mutations) the therapeutic effects of small-molecule correctors are still unclear. For these patients, there is still an unmet need for therapies to fit their particular molecular defects.

In the present study, we have evaluated the nature of four CFTR constructs bearing TMD mutants (G85E, E92K, L1077P, and M1101K), and our results shed light on how correctors can affect the CFTR interactome during ER processing to rescue the trafficking of CFTR mature form to the cell surface.

\section{Material and Methods}

\section{Cell culture}

The African green monkey fibroblast-like cell line, Cos-7 (catalog CRL-1651, ATCC) was maintained in Dulbecco's modified Eagle's medium (DMEM, Life Technologies) high glucose (1× glucose), supplemented with $10 \%$ fetal bovine serum (FBS, Invitrogen), penicillin $(100 \mathrm{U} / \mathrm{mL})$, and streptomycin $(100 \mu \mathrm{g} / \mathrm{mL})$ at $37^{\circ} \mathrm{C}$ in humidified incubator in 5\% $\mathrm{CO}_{2}$. Flp-In human embryonic kidney (HEK)-293 cells (catalog CRL1573, Life Technologies) cultured in DMEM containing 10\% FBS, penicillin (100 U/mL), streptomycin (100 $\mu \mathrm{g} / \mathrm{mL}$ ) and Zeocin $(100 \mu \mathrm{g} / \mathrm{mL})$ at $37^{\circ} \mathrm{C}$ were used to generate the stably transfected cell lines (see ref. [19]). CFBE41o- cells maintained in Eagle's essential medium (MEM, Invitrogen) with 10\% FBS, L-glutamate and penicillin/streptomycin were used to insert the Flp-In system and generate the stably transfected cell lines with each of the four CFTR mutants of interest. All cell lines were monitored for contamination.

\section{Transfection}

The wt-CFTR, G85E, E92K, $\Delta$ F508, L1077P and M1101K clones in the PBI-CMV 2 vector were transfected into Cos-7 cells. Transient transfection was performed using Lipofectamine 2000 (Invitrogen) according to the manufacturer's instructions. Forty-eight hours after the transfection, the cells were harvested and used for the experiments. To assess the ubiquitination of CFTR, ubiquitin plasmid (HA-tagged) was transfected into HEK-293 stably transfected cell lines for $48 \mathrm{~h}$.

\section{Generation of stably transfected cell lines}

The Flp-In System (catalog K6010-01, Invitrogen) is used for the generation of stable mammalian expression cell lines by taking advantage of a Saccharomyces cerevisiae-derived DNA recombination system. We first transfected CFBE41o- cells with the pFRT LacZeo plasmid to introduce the Flp-In construct into host cells. Zeocin-resistant clones were selected for the presence of the Flp-In construct.

CFTR constructs bearing TMD mutants (G85E, E92K, L1077P, and M1101K) were generated using a QuikChange Lightning Site-Directed Mutagenesis Kit (Agilent Technologies) and sub-cloned into the pcDNA5/FRT expression vector. The human CMV promoter controls the expression of the CFTR mutants in pcDNA5/FRT, and this vector also contains a hygromycin resistance gene with an FRT site embedded in the $5^{\prime}$ coding region.

Next, the pcDNA5/FRT vector containing the CFTR mutants and the p0G44 plasmid, which constitutively expresses the Flp recombinase under the control of human CMV promoter, were co-transfected into HEK-293 or CFBE41o- host cell lines containing the Flp-In construct by using Lipofectamine 2000. Upon co-transfection, the Flp recombinase expressed from pOG44 mediated a homologous recombination event between the FRT sites (integrated into the genome and on the pcDNA5/FRT) such that the pcDNA5/ FRT construct was inserted into the genome at the integrated FRT site. Hygromycin-resistant foci were isolated, expanded, and then analyzed for CFTR expression by immunoblotting.

\section{Treatment with inhibitors and correctors}

The degradation pathways were evaluated by exposing CFTR constructs bearing G85E, E92K, L1077P, or M1101K to a proteasome, aggresome, or two lysosome inhibitors (MG-132, tubacin, bafilomycin $\mathrm{A}_{1}$ and E-64, respectively) for $16 \mathrm{~h}$. Small-molecule correctors were applied for $16 \mathrm{~h}$ to evaluate the effect of them in rescuing CFTR: CFFT-002 (N-((1s,4s)-4-methylcyclohexyl)-5-(4-morpholinophenyl)-4-(oxetan-3-yloxy) pyrimidin-2-amine) and CFFT-003 (5-(2-cyclopropylbenzo[d] oxazol-5-yl)-N-((1s,4s)-4-methylcyclohexyl)4-(oxetan-3-yloxy)pyrimidin-2-amine) were generously provided by Martin Mense, and C3 (VRT-325; 4-cyclohexyloxy-2-\{1-[4-(4-methoxy-benzensulfonyl)-piperazin-1-yl]-ethyl\}-quinazoline), C4 (corr-4a; 


\section{Cellular Physiology Cell Physiol Biochem 2017;41:2194-2210 and Biochemistry Published online: April 24, $2017 \quad \begin{aligned} & \text { D 2017 The Author(s) } \\ & \text { www.karger.com/cpb }\end{aligned}$}

Lopes-Pacheco et al.: Correctors Rescue CFTR Transmembrane-Domain Mutants

N-[2-(5-chloro-2-methoxy-phenylamino)-4'-methyl-[4,5']bithiazolyl-2'-yl]-benzamide), and C18 (VRT-534; 1-(benzo[d][1,3]dioxol-5-yl)-N-(5-((S)-(2-chlorophenyl)((R)-3-hydroxypyrrolidin-1-yl)methyl)thiazol-2yl)cyclopropanecarboxamide) were obtained from the Cystic Fibrosis Foundation Therapeutics Panel Library. The last three compounds were used individually or in combinations of two. Dose-response experiments with increasing doses were performed, using 1, 5, 10, and $20 \mu \mathrm{M}$ for the correctors and tubacin; 1, 10, 50, and $100 \mu \mathrm{M}$ for bafilomycin $\mathrm{A}_{1}$ and E-64; and 1, 3, 5, and $10 \mu \mathrm{M}$ for MG-132. The two most effective doses are presented in the Results section. DMSO was used as vehicle $(0.2 \%, \mathrm{v} / \mathrm{v})$ to all compounds evaluated. The protein stability of CFTR was analyzed via cycloheximide administration ( $25 \mu \mathrm{g} / \mathrm{mL}$, Sigma). Cells were harvested 1, 2, 4, 6, or $8 \mathrm{~h}$ after protein translation was stopped by cycloheximide.

\section{Biotinylation of CFTR at the cell surface}

The plasma membrane proteins of Cos-7 cells transfected with CFTR bearing G85E, E92K, L1077P, or M1101K were incubated with EZ-Link ${ }^{\mathrm{TM}}$ sulfo-NHS-SS-biotin (5mg per each sample) (catalog 21331, Thermo Scientific) for $30 \mathrm{~min}$ at $4^{\circ} \mathrm{C}$. The cells were then washed gently three times with glycine quenching buffer (200 mM glycine and $25 \mathrm{mM}$ Tris- $\mathrm{HCl}, \mathrm{pH}$ 8.0, in DPBS plus $\mathrm{Ca}^{2+}$ and $\mathrm{Mg}^{2+}$ ) and solubilized in lysis buffer (50 mM Tris-HCl, pH 7.4, with $150 \mathrm{mM} \mathrm{NaCl}, 1 \%$ Nonidet P-40, and protease inhibitors). The lysates were rotated for $30 \mathrm{~min}$ at $4^{\circ} \mathrm{C}$, then centrifuged at $14,000 \times \mathrm{g}$ for $20 \mathrm{~min}$ at $4^{\circ} \mathrm{C}$. The total amount of cellular protein was determined using the Protein Assay Dye Reagent (Bio-Rad). The cellular surface proteins were isolated from the total lysate $(2,000 \mu \mathrm{g})$ by incubation with NeutrAvidin Plus UltraLink Resin (Thermo Scientific) for $45 \mathrm{~min}$ at $4^{\circ} \mathrm{C}(25 \mu \mathrm{g}$ of protein $/ 1 \mu \mathrm{L}$ of beads). After a brief centrifugation, the supernatant was discarded, and the beads were washed five times with lysis buffer. The bound proteins were eluted with $2 \times$ Laemmli sample buffer with $5 \% \beta$-mercaptoethanol. The eluted proteins were subjected to SDS-PAGE and immunoblotting as described below.

\section{Immunoblotting}

The cells were harvested and solubilized in lysis buffer (described in the section above) supplemented with protease inhibitor cocktail (catalog 78429, Thermo Scientific). The cell lysates were centrifuged at $14,000 \times g$ for $20 \mathrm{~min}$ at $4^{\circ} \mathrm{C}$ to pellet the insoluble material. The supernatants $(50 \mu \mathrm{g}$ of protein) were subjected to $10 \%$ SDS-PAGE and immunoblotting, followed by enhanced chemiluminescence (SuperSignal West Dura Extended Duration Substrate, catalog no. 34075, Thermo Scientific). The chemiluminescent signal on the polyvinylidene difluoride (PVDF) membrane (Bio-Rad) was directly captured by a FujiFilm LAS-4000 plus system with a cooled CCD camera. CFTR protein was detected with monoclonal anti-human CFTR antibody (217; 1:1,000; provided by Dr. J. Riordan, Department of Biochemistry and Biophysics and Cystic Fibrosis Center of North Carolina). Ezrin, used as a loading control, was detected with monoclonal antibody (1:10,000; sc-58758, Santa Cruz Biotechnology). The membranes were incubated with various primary antibodies to evaluate the interactions of CFTR mutants with proteostasis components: anti-HDAC6 (1:500; sc-11420), anti-HDAC7 (1:1,000; sc-74563), anti-VCP (1:1,000; sc-133125), anti-AHSA1 (1:1,000; H00010598-M01), anti-Hsp90 (1:1,000; 05-594), anti-Hsp70 (1:1,000; sc-66048), anti-Hsp40 (1:1,000; sc59554), anti-Hsp27 (1:500, sc-13132) and anti-HA (1:1,000, sc7392). Image Gauge version 3.2 software (Fuji Film) was used for densitometric quantification of the blots.

\section{Immunopreciptation}

Proteins were extracted, and the concentration was measured as described above. The protein lysates $(2,000 \mu \mathrm{g})$ were then rotated with $80 \mu \mathrm{L}$ of protein A/G-agarose beads (Santa Cruz Biotechnology) and $5 \mu \mathrm{g}$ of anti-CFTR antibody (M3A7, Millipore) for $4 \mathrm{~h}$ at $4^{\circ} \mathrm{C}$. The $\mathrm{A} / \mathrm{G}$ beads were washed four times with lysis buffer supplemented with protease inhibitor. Sample buffer $(2 \times)$ with $5 \% \beta$-mercaptoethanol was added 1:1 to the $A / G$ beads, and the protein samples were used for immunoblotting as described above. To evaluate the immunoprecipitation experiments, the densitometry of each proteostasis component was divided by the densitometry of CFTR $(B+C)$ and then these values were normalized for the untreated samples (value of "1"). This approach was used to evaluate how much of proteostasis components were interacting with CFTR mutants before and after the treatment with $\mathrm{C} 18+\mathrm{C} 4$.

Short-circuit currents

The short-circuit currents (Isc) were measured in Ussing-type chambers (Physiological Instruments). Confluent cystic fibrosis bronchial epithelial (CFBE41o-) cells stably expressing CFTR constructs bearing 


\section{Cellular Physiology Cell Physiol Biochem 2017;41:2194-2210 and Biochemistry Published online: April 24, $2017 \quad \begin{aligned} & \text { Do 2017 The Authors. } \\ & \text { www.karger.com/cpb }\end{aligned}$ \\ Lopes-Pacheco et al.: Correctors Rescue CFTR Transmembrane-Domain Mutants}

G85E, E92K, L1077P or M1101K were seeded onto 12-mm diameter Costar ${ }^{\circledR}$ Snapwell ${ }^{\mathrm{mi}}$ cell culture inserts (Corning Costar) and cultured for 7 days at $37^{\circ} \mathrm{C}$ to establish polarized monolayers. The inserts were mounted in an Ussing-type chamber and bathed in solutions (described below) maintained at $37^{\circ} \mathrm{C}$ and stirred by bubbling with $95 \% \mathrm{O}_{2}$ and $5 \% \mathrm{CO}_{2}$. Small-molecule correctors (C4, C18, C4+C18 or lumacaftor; $5 \mu \mathrm{M}$ of each) were added to the CFBE41o- cell culture medium $16 \mathrm{~h}$ before the experiments. Isc was measured by voltage clamping the transepithelial voltage across the monolayers to $0 \mathrm{mV}$ with a multichannel voltage-current clamp amplifier (model VCC MC6, Physiological Instruments). Transepithelial resistance was measured by periodically applying a 5-mV bipolar voltage pulse, recording the deflection response in Isc, and applying Ohm's law. The apical bath solution contained (in mM): 120 sodium gluconate, $2 \mathrm{CaCl}_{2}, 5 \mathrm{KCl}, 2 \mathrm{MgCl}_{2}, 10$ HEPES, and 10 D-glucose (adjusted to pH 7.3). The basolateral bath solution contained (in mM): $120 \mathrm{NaCl}$, $2 \mathrm{CaCl}_{2}, 5 \mathrm{KCl}, 2 \mathrm{MgCl}_{2}, 10 \mathrm{HEPES}$, and $10 \mathrm{D}$-glucose (adjusted to $\mathrm{pH} 7.3$ with $\mathrm{NaOH}$ ). Amiloride $(100 \mu \mathrm{M})$ was added to inhibit apical $\mathrm{Na}^{+}$absorption through epithelial sodium channel (ENaC). To activate the CFTR, the adenylate cyclase activator forskolin $(10 \mu \mathrm{M})$ and the tyrosine kinase inhibitor genistein $(30 \mu \mathrm{M})$ were added sequentially to the apical and basolateral bath solutions. Thiazolidonone CFTR inhibitor CFTR $_{\text {inh }} 172$ $(10 \mu \mathrm{M})$ was added to inhibit Isc, to establish that the measured current was CFTR-mediated chloride transport.

Data acquisition and analysis were performed with the Acquire and Analyze Data Acquisition System (version 2.3, Physiological Instruments). Data are expressed as the $\mathrm{CFTR}_{\mathrm{inh}} 172$-sensitive short-circuit current $\left(\Delta \mathrm{Isc}\right.$ ), calculated by subtracting the Isc measurement after $\mathrm{CFTR}_{\text {inh }} 172$ treatment from the values corresponding to the plateau phase reached after the addition of genistein to forskolin-stimulated Isc.

\section{Statistical assays}

Statistical comparisons were made by using one-way ANOVA followed by Tukey's test or an unpaired Student's $t$-test (Prism 5.0, GraphPad Software). All data are presented as means \pm SD. All measurements were done at least three times, and values were considered significant at $\mathrm{P}<0.05$.

\section{Results}

CFTR expression, thermal sensitivity, and degradation of G85E, E92K, L1077P and M1101K are mutation specific

To elucidate to what extent the mutants G85E, E92K, L1077P, and M1101K affect CFTR protein levels, we transiently transfected the CFTR constructs bearing the TMD mutants, as well as wild type (wt)-CFTR and $\Delta$ F508, into Cos-7 cells under the same experimental conditions (Fig. 1A). As expected, the mature form (band C) of $\Delta \mathrm{F} 508$ could barely be detected in the mutant products when compared to the wt-CFTR. The TMD mutants and $\Delta$ F508 showed similar amounts of the mature form. In addition, all the mutants showed less expression of the immature form (band B) than did wt-CFTR, and G85E, E92K, L1077P, and M1101K expressed even less of the immature form than did $\Delta$ F508. Fig. S1, shows the mutants stably expressed in CFBE410 cells (for all online suppl. material, see www.karger. com/doi/10.1159/000475578).

$\Delta \mathrm{F} 508$ creates an instability in NBD1 that is responsible for its biosynthetic arrest in the $\mathrm{ER}$, leaving it in an immaturely glycosylated form; however, its processing and function can be partially rescued by reducing the temperature at which the cells are incubated (to $27^{\circ} \mathrm{C}$, $v s$. human physiological temperature, $\left.37^{\circ} \mathrm{C}\right)[20,21]$. Based on the structural differences between TMDs and NBDs, we explored whether incubating cells at low temperature would rectify the lack of proper folding in CFTR constructs bearing TMD mutants (Fig. 1B-E). Both L1077P and M1101K expressed more of both the immature and mature forms when we grew the cells at lower temperature. In contrast, temperature correction affected only the immature form of E92K, and neither G85E nor E92K showed evidence of CFTR maturation when the cells were incubated at lower temperature.

ER components retain $\triangle \mathrm{F} 508-\mathrm{CFTR}$, forming an incompletely processed protein, which is ubiquitinated and undergoes proteasomal degradation [22]. We inhibited the various degradation pathways to understand how cells eliminate CFTR bearing G85E, E92K, 


\section{Cellular Physiology \\ Cell Physiol Biochem 2017;41:2194-2210 and Biochemistry

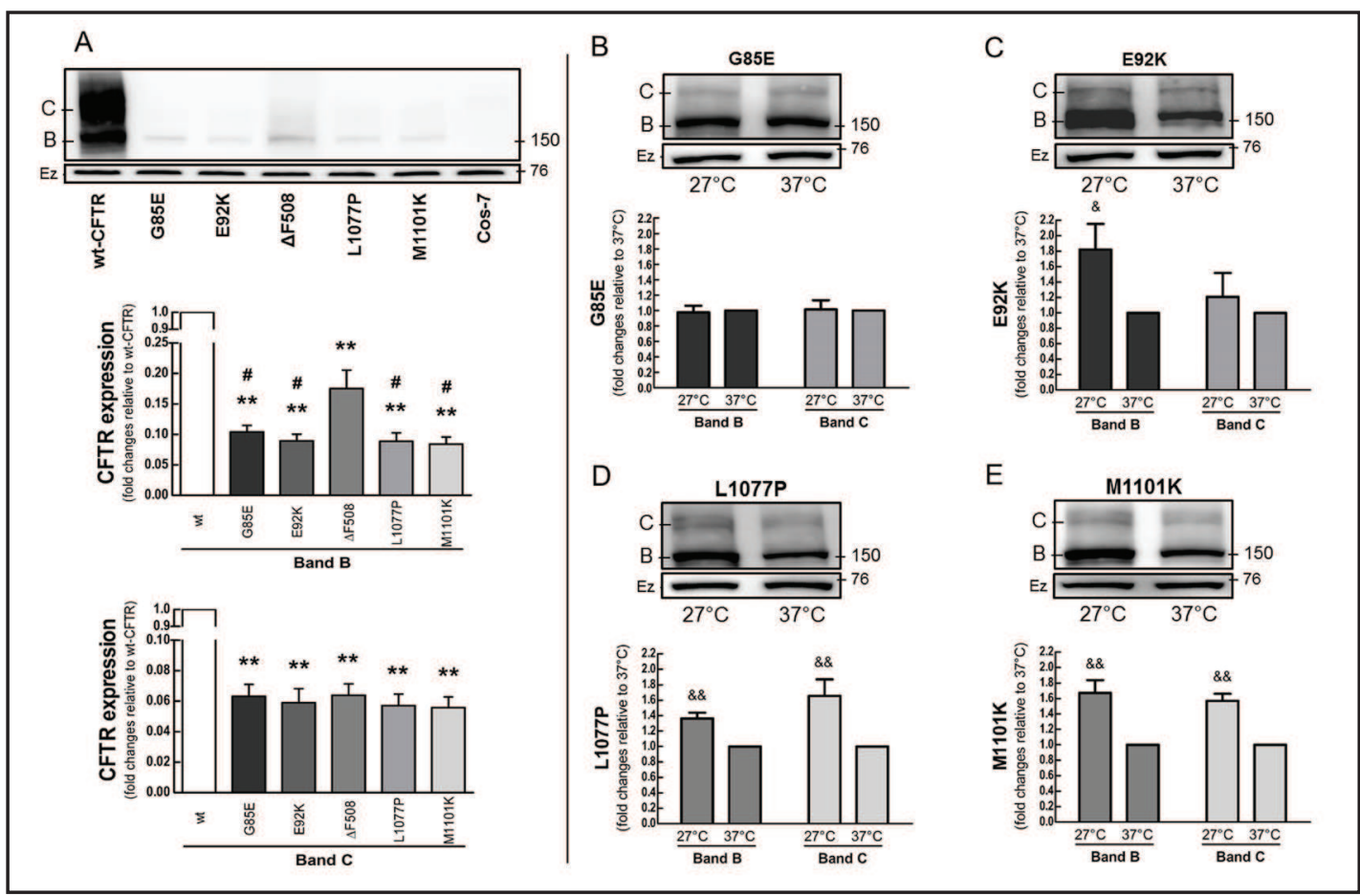

Fig. 1. Protein expression and thermal sensitivity of CFTR mutants. Cos-7 cells were transfected with 4 $\mu \mathrm{g}$ of wild type (wt)-CFTR or constructs bearing G85E, E92K, $\Delta$ F508, L1077P, or M1101K for 48 h. (A) Immunoblots and quantification of CFTR immature (band B) and mature (band C) forms, comparing wt-CFTR and mutants (ANOVA, $\mathrm{n}=3$ ). Data are normalized to wt-CFTR; vs. wt: ${ }^{* *} \mathrm{P}<0.01 ; v s . \Delta$ F508: ${ }^{*} \mathrm{P}<0.05$. (B-E) Cells were incubated at $27^{\circ} \mathrm{C}$ or $37^{\circ} \mathrm{C}$ for $24 \mathrm{~h}$ to evaluate the thermal sensitivity of (B) G85E, (C) E92K, (D) L1077P, and (E) M1101K (Student's $t$-test, $n=3$ ). Data are normalized to $37^{\circ} \mathrm{C} ; v s .37^{\circ} \mathrm{C}:{ }^{\&} \mathrm{P}<0.05$, \&\& $<0.01$. Ezrin (Ez) was used as a loading control. Membranes were cut into two strips and incubated with primary antibodies against CFTR or ezrin.

L1077P, or M1101K: MG-132 blocks the degradation of ubiquitin-conjugated proteins by proteasomes; tubacin inhibits the elimination of misfolded proteins by aggresomes; and bafilomycin $\mathrm{A}_{1}$ and E-64 prevent lysosomal degradation by inhibiting vacuolar-type $\mathrm{H}^{+}$ATPase and cysteine proteases, respectively (Fig. 2). MG-132 had the greatest effect on the CFTR mutants, sharply increasing their protein expression. Administration of tubacin also raised the amount of the mutant proteins present, but to a much lower extent than did MG132. In contrast, bafilomycin $A_{1}$ and E-64 affected only L1077P and produced no changes in G85E, E92K, or M1101K.

Correctors rescue CFTR expression and direct the mature forms to the cell surface

An increasing number of correctors have been evaluated for their ability to rescue CFTR bearing $\triangle F 508$, as well as other NBD mutations $[18,23,24]$. The impact of these small-molecules to restoring CFTR processing and trafficking in cells bearing the mutants G85E, E92K, L1077P, and M1101K has not yet been established. To answer this question, we incubated the cells bearing these mutants for $16 \mathrm{~h}$ with several correctors (see supplementary material, Fig. S2-S5): C3 and C18, discovered by Vertex Pharmaceuticals [25]; C4, developed by the Verkman lab [21]; and the CFFT compounds 002 and 003 [19, 24].

CFFT-002 and CFFT-003 had only a small or no effect on all four mutations. Similarly, C3, C4, and C18 had a small effect with regard to rescuing the maturation of CFTR bearing G85E, E92K, L1077P, or M1101K. C3 and C18 did not cause any additional rescue of the amount of immature and mature forms when we applied the compounds together, as opposed to individually. Co-administration of $\mathrm{C} 3$ and $\mathrm{C} 4$ showed additive effect and rescued more CFTR bearing E92K and L1077P, but had no such effect on CFTR bearing G85E and M1101K. Co- 


\section{Cellular Physiology Cell Physiol Biochem 2017;41:2194-2210

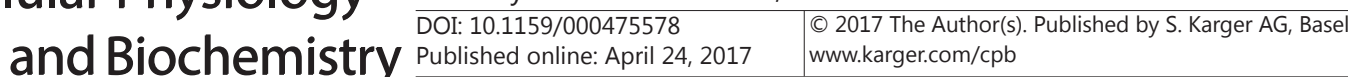

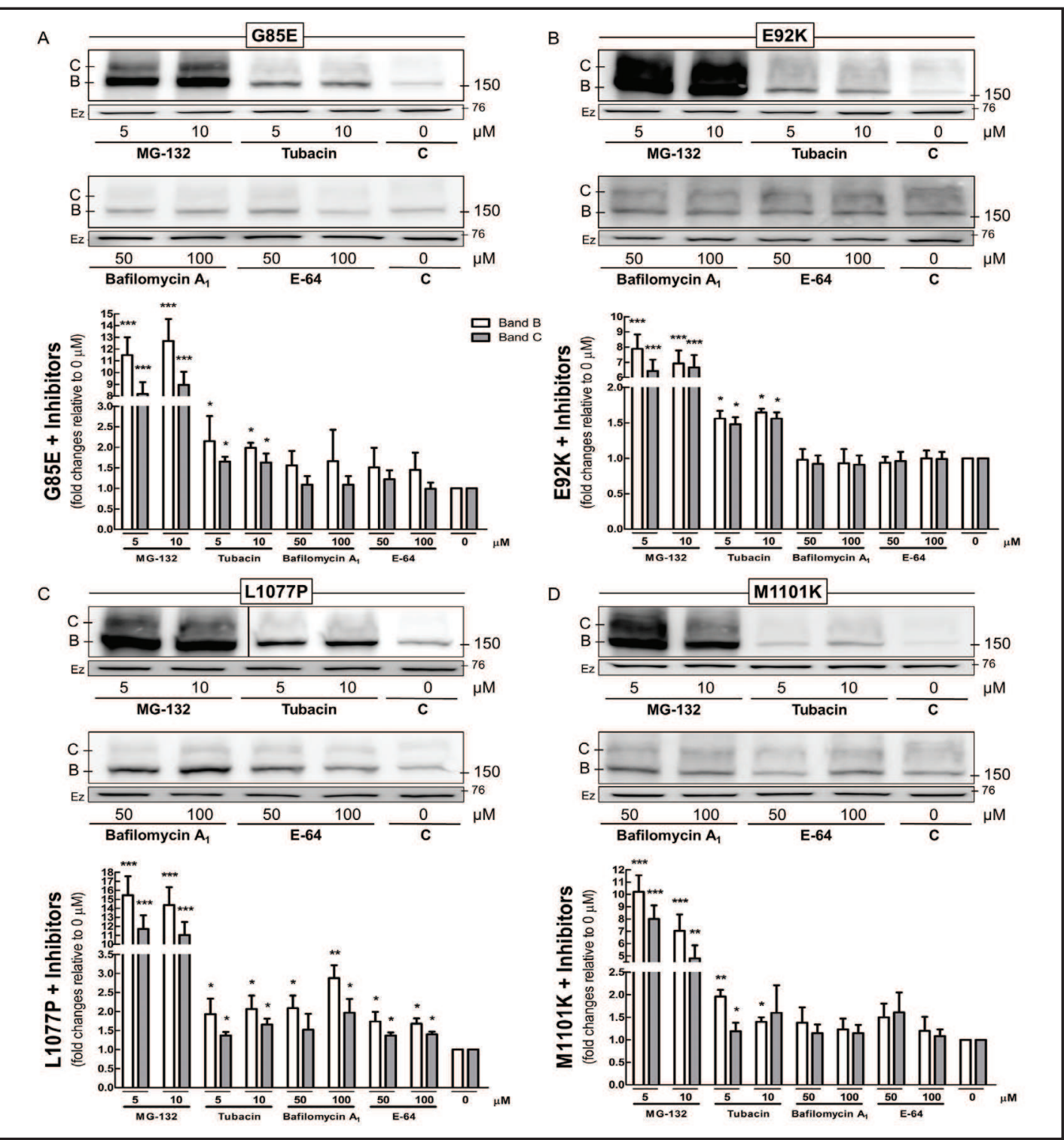

Fig. 2. Degradation pathway of CFTR mutants. Cos-7 cells transfected with $4 \mu \mathrm{g}$ of CFTR constructs bearing (A) G85E, (B) E92K, (C) L1077P, or (D) M1101K for $32 \mathrm{~h}$ were treated for additional $16 \mathrm{~h}$ with MG-132 (proteasome inhibitor), tubacin (aggresome inhibitor), or bafilomycin $\mathrm{A}_{1}$ or E-64 (lysosome inhibitors). Immunoblots and quantification of CFTR immature (band B) and mature (band C) forms (ANOVA, $\mathrm{n}=3-4$ ). Data are normalized to $0 \mu \mathrm{M}$ (control); vs. $0 \mu \mathrm{M}$ : ${ }^{*} \mathrm{P}<0.05$, ${ }^{*} \mathrm{P}<0.01,{ }^{* * *} \mathrm{P}<0.001$. Ezrin (Ez) was used as a loading control. C: control. Please note that the picture in Fig. $2 \mathrm{C}$ depicts experiments from the same gel but at two different exposures separated by a black line. Membranes were cut into two strips and incubated with primary antibodies against CFTR or ezrin.

administration C4 and C18 had the greatest effect and raised the CFTR maturation by 3.5to 5.0 -fold in the mutations E92K, L1077P, and M1101K. Co-administration of C4 and C18 also provided the best correction to the mutant G85E, but this effect was weaker than that observed for the other three mutants. Therefore, we used the co-administration of $\mathrm{C} 4$ and C18 to understand how the correctors could rescue CFTR bearing G85E, E92K, L1077P, and M1101K.

Since the correctors increased the maturation of CFTR mutants, we biotinylated the proteins at the plasma membrane to evaluate whether the CFTR mature form had trafficked to the cell surface (Fig. 3). The mutants E92K, L1077P, and M1101K expressed the CFTR 
Fig. 3. Co-administration of $\mathrm{C} 4$ and $\mathrm{C} 18$ restores the expression of the mature form of CFTR mutants at the cell surface. Cos-7 cells transfected with $4 \mu \mathrm{g}$ of CFTR constructs bearing G85E, E92K, L1077P, or M1101K for $32 \mathrm{~h}$ were treated with C4 and C18 (each 5 $\mu \mathrm{M}$ ) for additional $16 \mathrm{~h}$. Immunoblots show the effect of $\mathrm{C} 4$ and C18 on CFTR mutants in (A) the total protein lysate (TL) and (B) biotinylation of cell-surface proteins (BS). (C) The mature form (band C) of the CFTR mutants at the cell surface was quantified in untreated and treated samples (Student's $t$ test, $\mathrm{n}=4$ ). Data are normalized to control (untreated samples) values; $v s$. control: ${ }^{* *} \mathrm{P}<$ 0.01. Ezrin (Ez), an intracellular
A

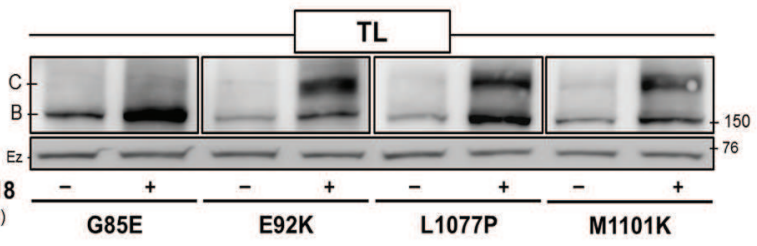

B

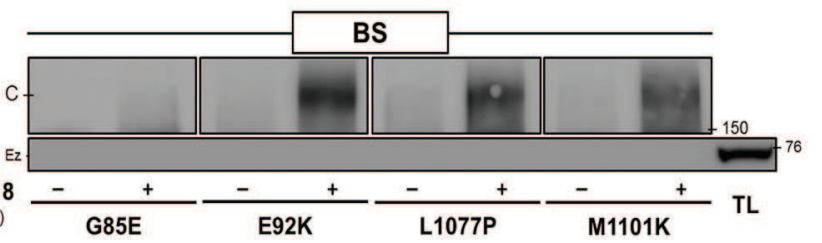

C

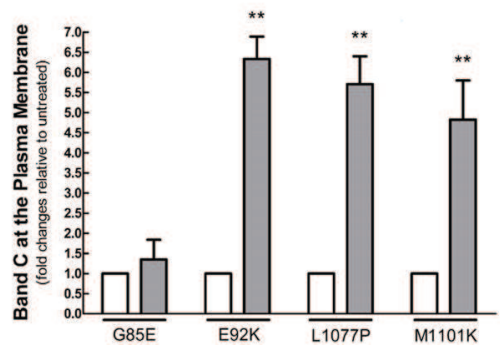

protein, was used as a loading control. The lack of ezrin binding to biotin is evidence that the plasma membrane was intact and biotin did not leak into the cells. Membranes were cut into two strips and incubated with primary antibodies against CFTR or ezrin.

mature form at the plasma membrane after co-administration of C4 and C18. Despite the correctors having increased the protein expression of CFTR bearing G85E, the mature form of this mutant product did not reach the cell surface.

\section{Correctors remodel the CFTR interactome}

Proteostasis networks interconnect gene expression, signaling pathways, molecular chaperones, and degradation systems to maintain a healthy proteome $[1,4]$. The wt-CFTR and $\Delta$ F508 interact differently with proteostasis components that enable wt-CFTR maturation and preclude $\triangle \mathrm{F} 508$ exit from the ER [2]. We explored the binding of proteins involved in ERAD to CFTR constructs bearing G85E, E92K, L1077P, or M1101K, and also asked whether correctors may modulate their interactomes to rescue CFTR. For this purpose, we performed co-immunoprecipitation (co-IP) assays with five chaperones/co-chaperones: the heat shock proteins (Hsps) 27, 40, 70, and 90; and the activator of Hsp 90-kDa protein ATPase homolog 1 (AHSA1). Hsp27 (also known as HspB1) connects $\triangle$ F508-CFTR with small ubiquitin-like modifier (SUMO)-2/3 for degradation via SUMOylation [26]. Hsp40 (DnaJ) is a co-chaperone that forms an 'ER trap' with the chaperones Hsp70 and Hsp90 to degrade $\Delta$ F508-CFTR via the $26 \mathrm{~S}$ proteasome [27]. The ATPase activity of Hsp90 is controlled by its co-chaperone AHSA1 $[28,29]$.

In addition to evaluating these molecular chaperones, we analyzed the interaction of CFTR constructs bearing the TMD mutants with vasolin-containing protein (VCP or p97) and the histone deacetylases (HDACs) 6 and 7.VCP and HDAC6 translocate misfolded proteins to proteasomes and aggresomes, respectively, for elimination [30, 31]. Furthermore, inhibition of HDAC7 or VCP rescues the trafficking and function of CFTR bearing $\triangle F 508$ [32, 33].

Analysis of total protein lysates showed that co-administration of $\mathrm{C} 4$ and $\mathrm{C} 18$ decreased the expression levels of AHSA1, Hsp70, and Hsp27 in cells bearing G85E-CFTR; it decreased the expression levels of VCP, AHSA1, and Hsp90, 70, and 27 in cells bearing E92K-CFTR (Fig. 4A), and it produced no changes in the steady-state levels of ERAD proteins tested in cells bearing L1077P- or M1101K-CFTR (Fig. 5A). Correctors also affected the amount of ERAD proteins precipitated; the amount of Hsp40 was reduced in all four mutations (Fig. 


\section{Cellular Physiology Cell Physiol Biochem 2017;41:2194-2210 \begin{tabular}{c|l} 
DOI: 10.1159/000475578 & $\begin{array}{l}\text { O } 2017 \text { The Author(s). Published by S. Karger AG, Basel } \\
\text { www.karger.com/cpb }\end{array}$
\end{tabular}

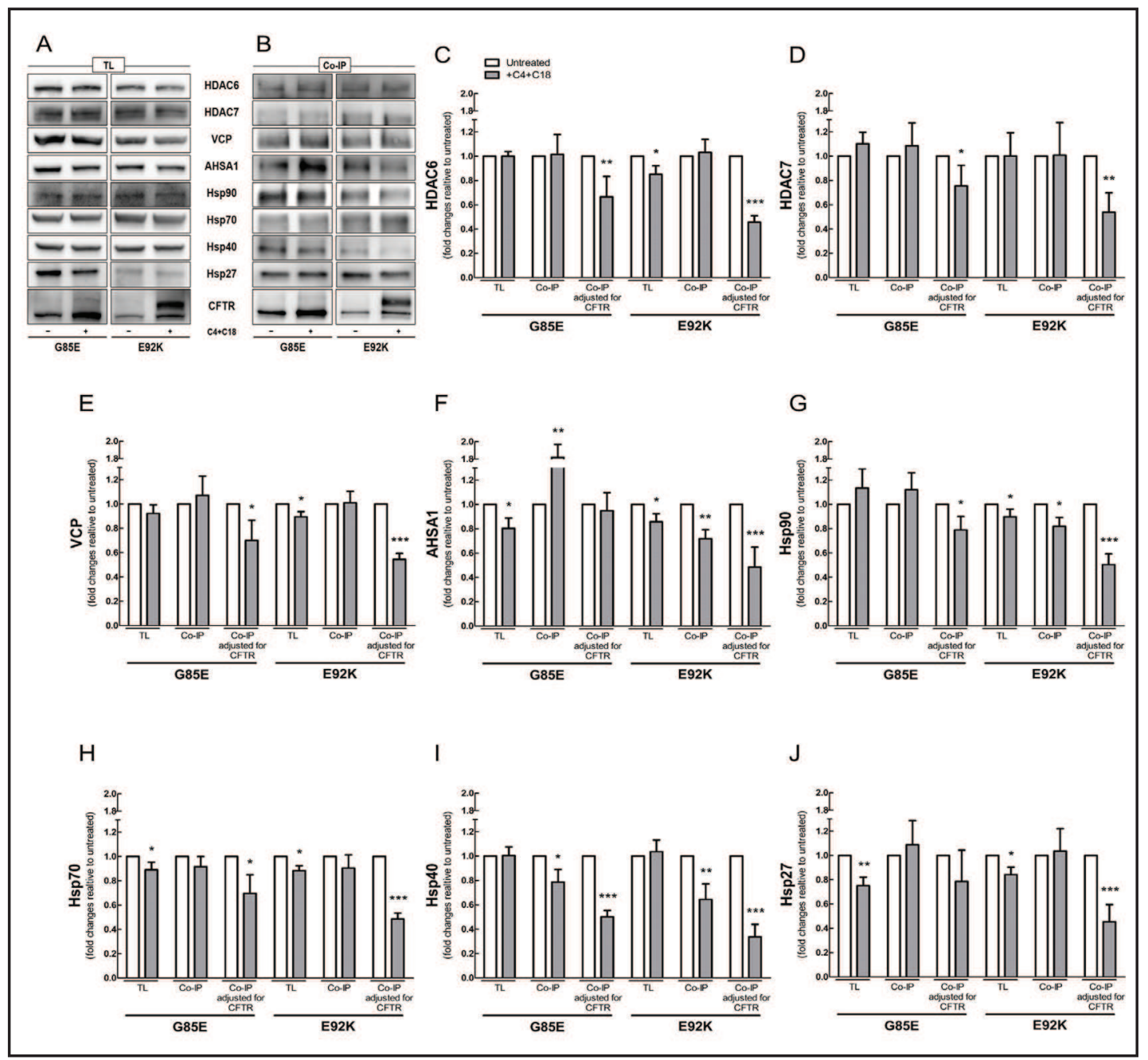

Fig. 4. Co-administration of C4 and C18 mitigates the binding of CFTR bearing G85E and E92K to proteostasis components. HEK-293 cell lines stably expressing CFTR constructs bearing G85E or E92K were treated with $\mathrm{C} 4$ and $\mathrm{C} 18$ (each $5 \mu \mathrm{M}, 16 \mathrm{~h}$ ). CFTR was immunoprecipitated with anti-CFTR antibody M3A7. Samples from (A) total protein lysate (TL) and (B) co-immunoprecipitation (co-IP) were subjected to immunoblotting, and membranes were incubated with different primary antibodies as detailed in Materials and Methods. (C-J) Quantification of blots from TL, co-IP, and co-IP adjusted for the total amount of CFTR, immunoprecipitated with antibody against (C) HDAC6, (D) HDAC7, (E) VCP, (F) AHSA1, (G) Hsp90, (H) Hsp70, (I) Hsp40, or (J) Hsp27 (Student's t-test, $\mathrm{n}=4$ ). Data are normalized to control (untreated sample) values; vs. control: ${ }^{*} \mathrm{P}<0.05,{ }^{* *} \mathrm{P}<0.01,{ }^{* * *} \mathrm{P}<0.001$. For this experiment, three to four gels were loaded with the same samples and then membranes were cut into two to three pieces to incubate each piece with a specific primary antibody. Each blot was reprobed for ezrin for the loading control.

$4 \mathrm{~B}$ and $5 \mathrm{~B})$. The responses of the remaining proteins were more variable, depending on the CFTR mutant: in the case of G85E-CFTR, more AHSA1 was precipitated; for E92K-CFTR, less AHSA1 and Hsp90; for L1077P-CFTR, less VCP and Hsp27; and for M1101K-CFTR, less HDAC6, VCP, and Hsp70. To calculate how much of the ERAD proteins were bound to CFTR mutants before and after the treatment with correctors, we used the quantity of each protein precipitated per total amount of CFTR pulled down (Fig. 4C-J and 5C-J). The interactions of ERAD components with the four CFTR mutants were mitigated after co-administration of C4 and C18, with exception of AHSA1 and Hsp27 with CFTR bearing G85E. 


\section{Cellular Physiology Cell Physiol Biochem 2017;41:2194-2210 \begin{tabular}{l|l} 
DOI: 10.1159/000475578 & $\begin{array}{l}\text { O } 2017 \text { The Author(s). Published by S. Karger AG, Basel } \\
\text { www.karger.com/cpb }\end{array}$
\end{tabular}

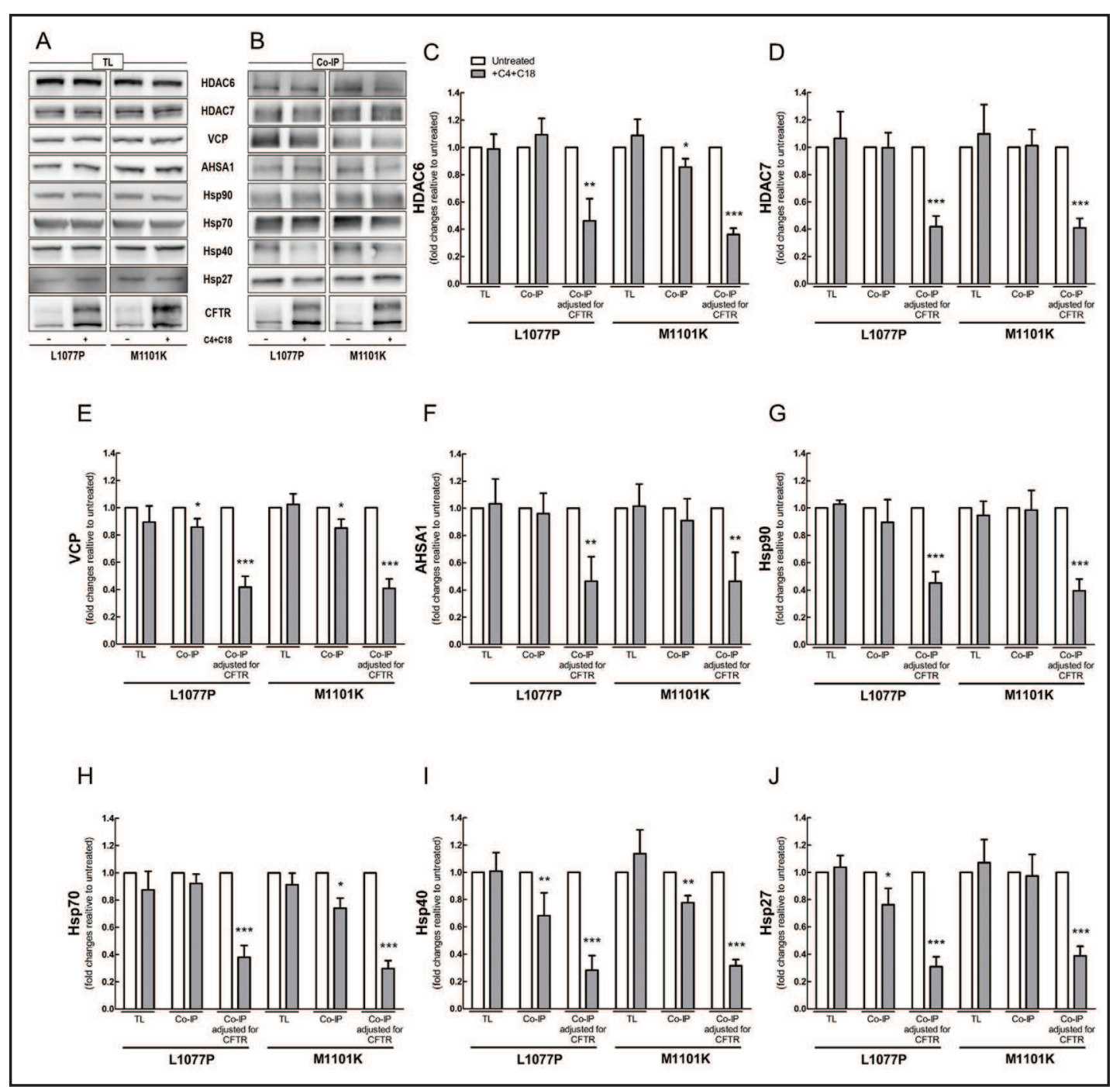

Fig. 5. Co-administration of C4 and C18 mitigates the binding of CFTR bearing L1077P and M1101K to proteostasis components. HEK-293 cell lines stably expressing CFTR constructs bearing L1077P or M1101K were treated with C4 and C18 (each $5 \mu \mathrm{M}, 16 \mathrm{~h}$ ). CFTR was immunoprecipitated with anti-CFTR antibody M3A7. Samples from (A) total protein lysate (TL) and (B) co-immunoprecipitation (co-IP) were subjected to immunoblotting, and membranes were incubated with different primary antibodies as detailed in Materials and Methods. (C-J) Quantification of blots from TL, co-IP, and co-IP, adjusted for the total amount of CFTR immunoprecipitated with antibody against (C) HDAC6, (D) HDAC7, (E) VCP, (F) AHSA1, (G) Hsp90, (H) Hsp70, (I) Hsp40, or (J) Hsp27 (Student's $t$-test, $\mathrm{n}=4$ ). Data are normalized to control (sample untreated) values; vs. control: ${ }^{*} \mathrm{P}<0.05,{ }^{* *} \mathrm{P}<0.01,{ }^{* * *} \mathrm{P}<0.001$. For this experiment, three to four gels were loaded with the same samples and then membranes were cut into two to three pieces to incubate each piece with a specific primary antibody. Each blot was reprobed for ezrin for the loading control.

After ER components arrest the misfolding CFTR, the mutated protein is polyubiquitinated and subsequently eliminated [30,34]. Co-administration of C4 and C18 reduced the amount of ubiquitin precipitated with CFTR, as well as the binding of ubiquitin to CFTR bearing E92K, L1077P, or M1101K (Fig. 6B-D). In contrast, CFTR bearing G85E did not show any reduction in ubiquitination after the co-administration of correctors (Fig. 6A).

Correctors raise CFTR stability and rescue channel function

The wt-CFTR forms a fairly stable protein with long half-life, whereas $\Delta \mathrm{F} 508$ creates an instability in CFTR that reduces its half-life $[35,36]$. We blocked protein synthesis by 


\section{Cellular Physiology \\ Cell Physiol Biochem 2017;41:2194-2210 and Biochemistry

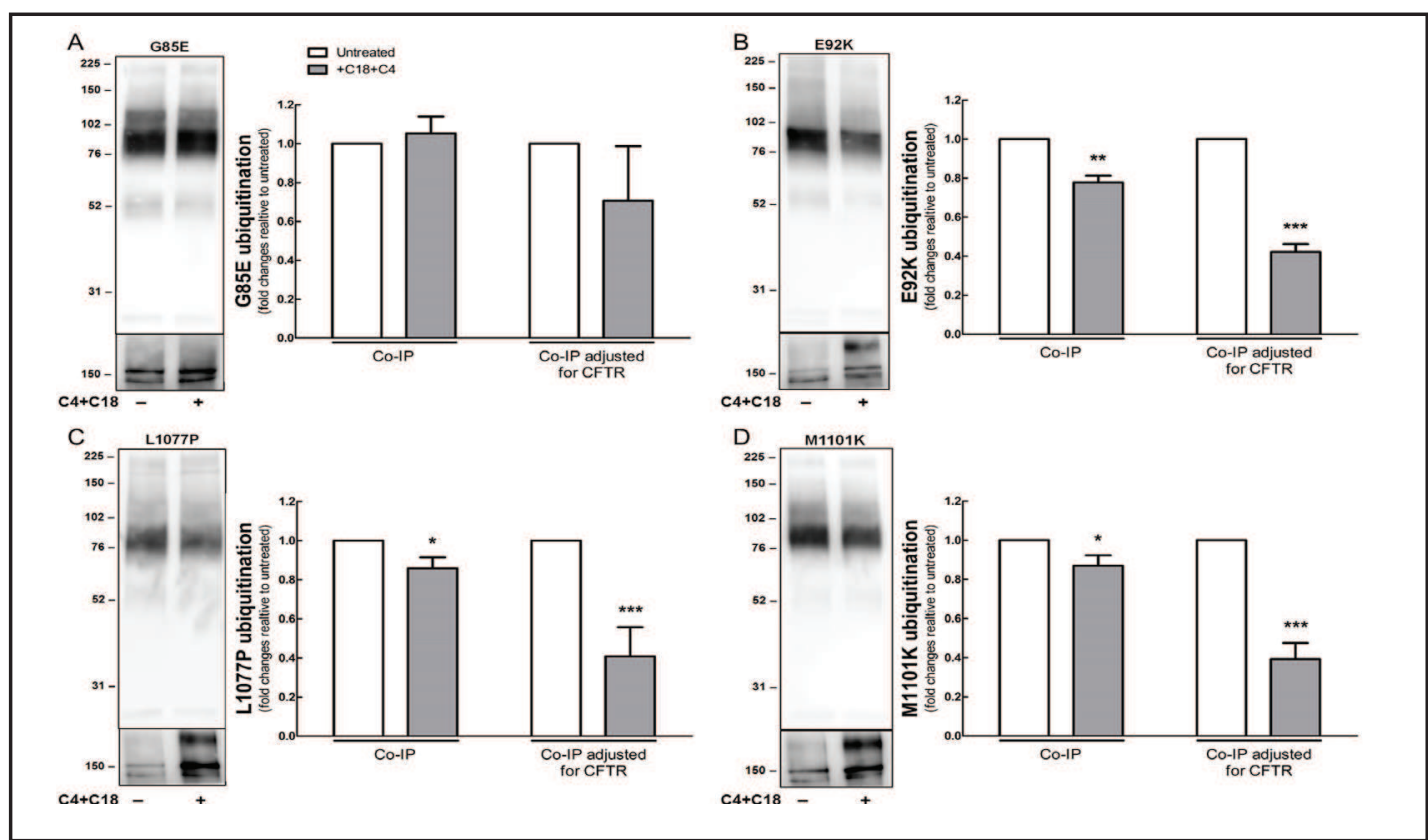

Fig. 6. Co-administration of $\mathrm{C} 4$ and $\mathrm{C} 18$ reduces ubiquitination of CFTR mutants. HEK-293 cell lines stably expressing CFTR constructs bearing (A) G85E, (B) E92K, (C) L1077P, or (D) M1101K were transfected with ubiquitin plasmid (HA-tagged) for $32 \mathrm{~h}$ and then treated with $\mathrm{C} 4$ and C18 (each $5 \mathrm{uM}$ ) for additional $16 \mathrm{~h}$. CFTR was immunoprecipitated with anti-CFTR antibody M3A7. Samples from co-immunoprecipitation (coIP) were subjected to immunoblotting, and membranes were incubated with anti-HA (top) and anti-CFTR (bottom) primary antibodies. Quantification of blots from co-IP and co-IP, adjusted for the total amount of CFTR immunoprecipitated (Student's $t$-test, $\mathrm{n}=4$ ). Data are normalized to control (untreated sample) values; vs. control: ${ }^{*} \mathrm{P}<0.05,{ }^{* *} \mathrm{P}<0.01,{ }^{* * *} \mathrm{P}<0.001$. For this experiment, two gels were loaded with the same samples and each membrane was incubated with specific primary antibody against HA (top) or CFTR (bottom). Each blot was reprobed with ezrin as a loading control.

applying cycloheximide to the cells and then evaluated the rate of disappearance of the protein as evidence of stability or degradation of CFTR bearing G85E, E92K, L1077P, or M1101K (Fig. 7). During the time course of the cycloheximide treatment, all four mutants showed a decreased amount of the immature form, and the little amount of mature form detected at $0 \mathrm{~h}$ rapidly disappeared. As mentioned previously, co-administration of $\mathrm{C} 4$ and C18 increased the expression of both immature and mature forms in CFTRs bearing any of the four TMD mutants, and after $8 \mathrm{~h}$ of cycloheximide exposure, the constructs bearing E92K, L1077P, and M1101K showed an approximately 4-fold increase in the mature form when compared to the controls (untreated samples at $0 \mathrm{~h}$ ). For the CFTR bearing E92K, there was a slow decline in the mature form during the time course of the cycloheximide treatment, whereas for the CFTR bearing L1077P or M1101K, there was a quick decay during the first 2 $\mathrm{h}$, followed by a slow decline. In contrast, CFTR bearing G85E showed little of the immature form after $8 \mathrm{~h}$ of cycloheximide treatment, and the mature form totally vanished after $4 \mathrm{~h}$.

We then determined whether administration of correctors could rescue a functional CFTR protein, by measuring the short-circuit currents (Isc) in polarized monolayers of CFBE410- cells stably expressing CFTR bearing G85E, E92K, L1077P, or M1101K (Fig. 8). As expected, CFTR bearing G85E did not show channel function (data not shown), corroborating with the biotinylation experiments in which correctors did not rescue the mature form of this mutant to the cell surface. When we grew the cells at $37^{\circ} \mathrm{C}$ and treated those expressing the mutant E92K, L1077P, or M1101K with C4, C18, or C4+C18, we observed a 2.5- to 6.0fold increase in Isc, with only a synergistic effect of co-administration of C4 and C18 in cells expressing CFTR bearing E92K. When the cells were grown at $27^{\circ} \mathrm{C}$ and subsequently treated with correctors, we noted the same or even less Isc, when compared to those cells 


\section{Cellular Physiology Cell Physiol Biochem 2017;41:2194-2210

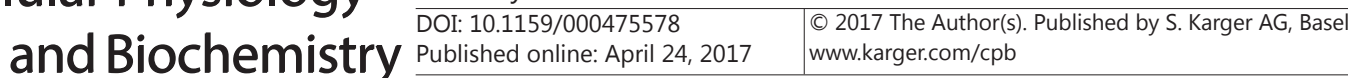
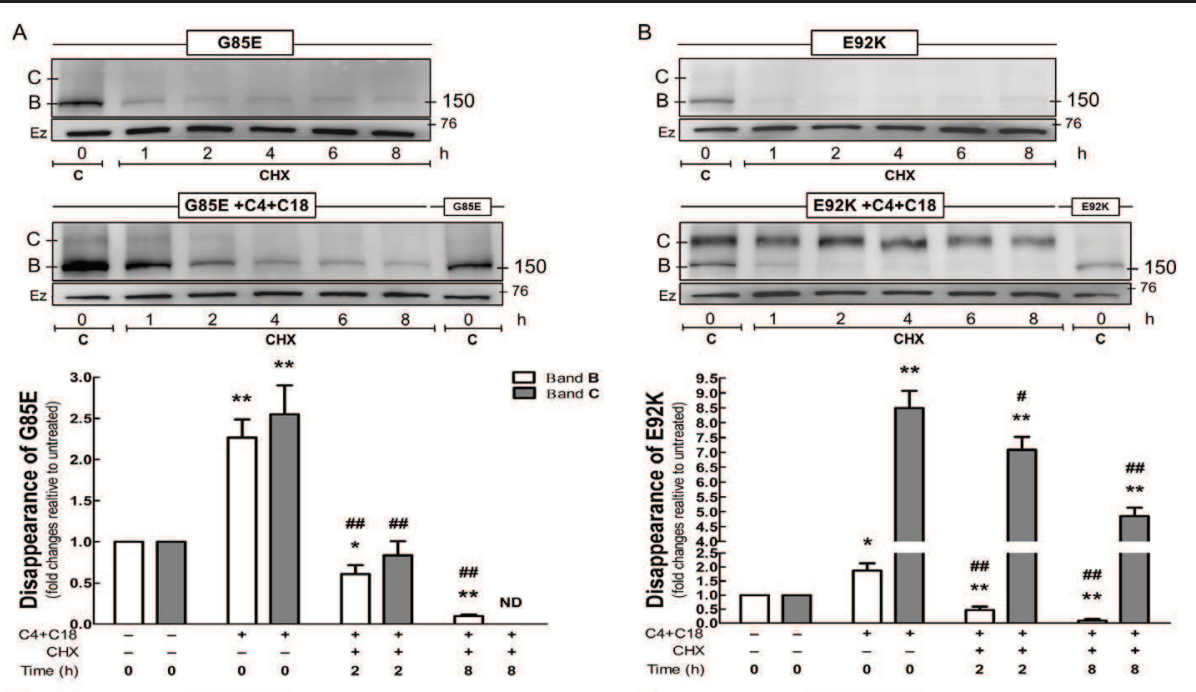

C

D
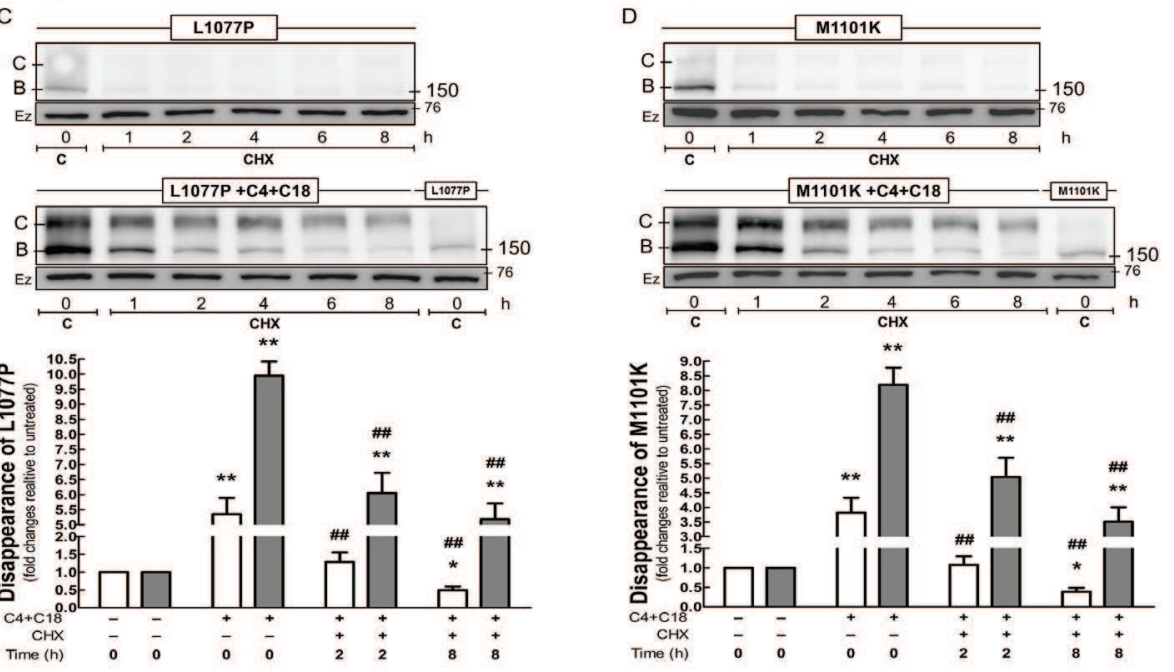

Fig. 7. Co-administration of C4 and C18 enhance the protein stability of CFTR mutants. HEK-293 cell lines stably expressing the G85E, E92K, L1077P, or M1101K constructs were treated with C4 and C18 (each 5 $\mu \mathrm{M}, 16 \mathrm{~h}$ ). Subsequently, protein synthesis was blocked by applying cycloheximide (CHX, $25 \mu \mathrm{M} / \mathrm{mL}$ ), and cells were harvested at different time points (0-8 h). Immunoblots and quantification of CFTR bearing (A) G85E, (B) E92K, (C) L1077P, and (D) M1101K (ANOVA, $n=4$ ). Data are normalized to control (untreated sample) values; vs. $0 \mathrm{~h}$ without $\mathrm{C} 4+\mathrm{C} 18$ : ${ }^{*} \mathrm{P}<0.05$, ${ }^{* *} \mathrm{P}<0.01$; vs. 0 h with $\mathrm{C} 4+\mathrm{C} 18$ : ${ }^{\#} \mathrm{P}<0.05$, ${ }^{\# \#} \mathrm{P}<0.01$; ND: not detected. Bars represent densitometric quantification of immature band $\mathrm{B}$ (white) and mature band $\mathrm{C}$ (gray). Ezrin (Ez) was used as a loading control. C: control = untreated without CHX. The chase time are from 1-8hrs. Membranes were cut into two strips and incubated with primary antibodies against CFTR or ezrin.

grown at $37^{\circ} \mathrm{C}$ and expressing CFTR bearing E92K, L1077P, or M1101K. Treating the cells with lumacaftor after growth at $37^{\circ} \mathrm{C}$ rescued CFTR function in those expressing the mutant E92K or M1101K, but only to the same extent as did the co-administration of C4 and C18. Intriguingly, when we grew the cells at $27^{\circ} \mathrm{C}$ and applied lumacaftor, we observed either the same, more or less Isc for CFTR bearing E92K, L1077P, and M1101K, respectively, when compared to the same cells grown at $37^{\circ} \mathrm{C}$.

\section{Discussion}

In the present study, we have characterized four CFTR mutants in TMD (G85E, E92K, $\mathrm{L} 1077 \mathrm{P}$, and $\mathrm{M} 1101 \mathrm{~K}$ ) and shown that a combination of correctors can rescue CFTR 


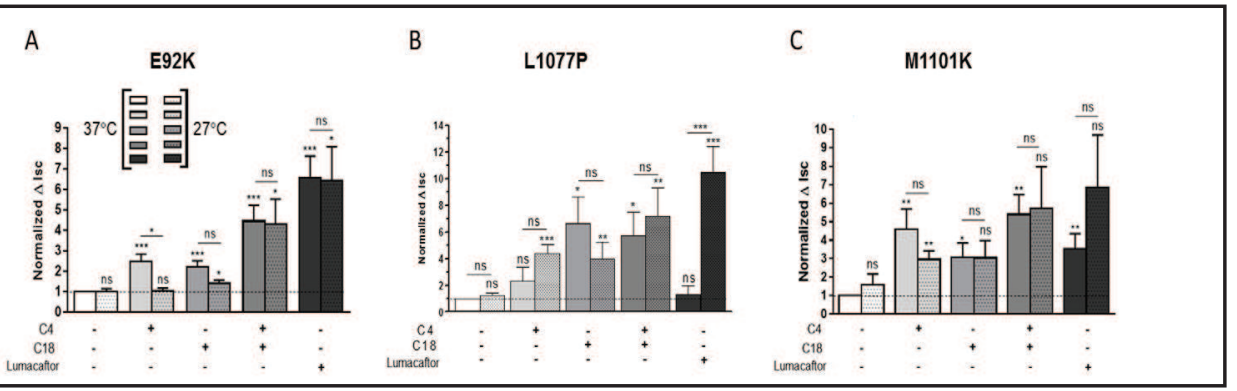

Fig. 8. Co-administration of C4 and C18 rescues the channel function of CFTR mutants. CFBE41o- cell lines stably expressing the $\mathrm{E} 92 \mathrm{~K}, \mathrm{~L} 1077 \mathrm{P}$, or $\mathrm{M} 1101 \mathrm{~K}$ constructs were maintained at $37^{\circ} \mathrm{C}$ or $27^{\circ} \mathrm{C}$ for $24 \mathrm{~h}$ and then treated with $\mathrm{C} 4, \mathrm{C} 18, \mathrm{C} 4+\mathrm{C} 18$, or lumacaftor (each $5 \mu \mathrm{M}$, for $16 \mathrm{~h}$ ). The short-circuit current (Isc) responses (all measured at $37^{\circ} \mathrm{C}$ ) from cells bearing CFTR constructs (A) E92K, (B) L1077P, or (C) M1101K are shown. Data are expressed as the $\mathrm{CFTR}_{\text {inh }} 172$-sensitive Isc $(\Delta \mathrm{Isc})$, calculated by subtracting the Isc after $\mathrm{CFTR}_{\text {inh }} 172$ treatment from the peak forskolin/genistein-stimulated Isc. Smooth (left) bars are associated with $37^{\circ} \mathrm{C}$ incubation, and dotted (right) bars with $27^{\circ} \mathrm{C}$. Statistical significance is presented as: ${ }^{\text {ns }}$ no significant difference, ${ }^{*} \mathrm{P}<0.05,{ }^{* *} \mathrm{P}<0.01,{ }^{* * *} \mathrm{P}<0.001$ ( $\mathrm{n}=4-12$ for each condition) compared to control conditions $\left(37^{\circ} \mathrm{C}, \mathrm{n}=4-12\right.$ and $\left.27^{\circ} \mathrm{C}, \mathrm{n}=4-5\right)$. Amiloride $(100 \mu \mathrm{M})$ was present during the whole experiment to avoid interference by ENaC-mediated $\mathrm{Na}^{+}$currents.

expression and function in three of them. Like $\Delta \mathrm{F} 508$, the mutations G85E, E92K, L1077P, and M1101K are class II mutants and cause disruption of CFTR processing. ERAD components recognize the mutated CFTR as improperly folded and arrest the protein, precluding its full maturation. Intriguingly, $\Delta$ F508 expressed more immature-form CFTR than did the other four mutants, possibly indicating that they are more rapidly degraded. The results of exposure of CFTR bearing G85E, E92K, L1077P, or M1101K to inhibitors indicated that these four mutants share a similar degradation pattern with $\Delta$ F508. The ubiquitin-dependent proteasomes eliminated the largest amount of the misfolded proteins, and aggresomes destroyed the remaining portions by autophagy.

$\Delta \mathrm{F} 508$ is a temperature-sensitive mutant, and incubation of cells at low temperature can partially restore its processing, trafficking and function [20,21,37]. In contrast to $\Delta F 508$, which is located at NBD1, G85E and E92K are situated at MS1 in TMD1 [11]. Both G85E and E92K are translated at the beginning of CFTR synthesis, and these mutations destabilize CFTR by disrupting ER targeting, its integration profile, and/or topology formation [38]. The mutant at position 85 substitutes a nonpolar amino acid for a negatively charged one (glycine for glutamate), introducing an ionizable group within the MS1 sequence. At position 92, the change of glutamate to lysine alters the charge of the side chain (negative to positive). Our results showed that low-temperature incubation did not cause maturation of either G85E or E92K, and G85E produced a more aberrant protein, since E92K still presented ER accumulation of core glycosylated protein. On the other hand, L1077P and M1101K are located at ICL4 and MS11 in TMD2, respectively [10], which directly interacts with NBD1 and forms interdomain interactions [5]. At positions 1077 and 1101, these mutations change amino acids with hydrophobic side chains for nonpolar (leucine to proline) and positively charged (methionine to lysine) amino acid residues, respectively. Cells bearing both L1077P and M1101K expressed more immature and mature forms of CFTR upon low-temperature incubation, although this increase occurred to a lesser extent than previously observed for $\Delta \mathrm{F} 508[20,21,37]$. Therefore, incubation of cells at low temperature was associated with a lesser efficiency in rectifying CFTR folding to the mutants L1077P and M1101K.

Several CFTR mutants present multiple defects, including $\Delta \mathrm{F} 508$, in which the major characteristic is NBD1 instability, leading to misfolded protein [22,34]; however, this mutant also affects channel gating [5,6] and cell-surface stability [7,36]. Monotherapy with lumacaftor or ivacaftor has proven ineffective in improving the lung function of $\Delta \mathrm{F} 508$-homozygotes patients $[15,16]$, but co-administration of lumacaftor/ivacaftor produces significant, albeit modest, clinical improvement in these patients $[17,18]$. These results suggest that mutants 


\section{Cellular Physiology Cell Physiol Biochem 2017;41:2194-2210 and Biochemistry Poblisned online: April Z4, $2017 \quad \begin{aligned} & \text { D 2017 The Author(s. } \\ & \text { www.karger.com/cpb }\end{aligned}$ \\ Lopes-Pacheco et al.: Correctors Rescue CFTR Transmembrane-Domain Mutants}

with multiple defects may require drug combinations to achieve therapeutic levels that could benefit patients. Like $\Delta \mathrm{F} 508[23,37]$, the mutants G85E, E92K, L1077P, and M1101K are associated with multiple defects, and the greatest rescue of CFTR bearing these mutants was obtained when we applied two correctors together that have different mechanisms of action (i.e., C4+C18). C18 is a class I corrector that stabilizes the interactions between NBD1 and ICL1/4, whereas C4 is a class II corrector that restores NBD2 stability and its interdomain interactions [23]. Co-administration of $\mathrm{C} 18$ and C4 rescued the trafficking of mature-form CFTR bearing E92K, L1077P, or M1101K to the cell surface; however, this treatment was unsuccessful in fully restore the trafficking of CFTR bearing G85E to the plasma membrane.

New pharmacological treatments may rectify the defective CFTR structure directly by binding to the mutated protein and/or indirectly by remodeling cellular proteostasis, thereby allowing sufficient time for the protein to reach conformational stability. Each specific protein uses only a subset of the proteostasis network components in a cellular environment, which include chaperones/co-chaperones, as well as folding, trafficking, and degradation factors. CFTR bearing $\triangle \mathrm{F} 508$ has a prolonged association with proteostasis components at the ER, and these components target the CFTR for ubiquitination and degradation $[1,2]$. CFTR bearing G85E, E92K, L1077P, or M1101K connects to a proteostasis network similar to that observed in previous studies for $\Delta \mathrm{F} 508$, which might explain the similarities in their degradation. When we co-administered C4 and C18, CFTR bearing any of the four TMD mutants expressed more immature and mature forms, and they showed mitigated binding to proteostasis components. In particular, Hsp40 presented the same pattern of decreased coimmunoprecipitation and binding to CFTR bearing G85E, E92K, L1077P, or M1101K after the co-administration of correctors. Previous reports have shown that Hsp40 forms a 'chaperone trap' with Hsp70/Hsp90 [27] and also cooperates with the COPII machinery to sequester misfolded CFTR into ER-associated compartments [39]. Therefore, its mitigated interaction with CFTR mutants may prevent protein retention and degradation by proteasomes.

The results were more variable for the remaining proteostasis components evaluated. Co-administration of C4 and C18 allowed a functional protein to reach the cell surface in the case of CFTR bearing E92K, L1077P, or M1101K, by mitigating their interactions with proteostasis components and ubiquitination. Intriguingly, CFTR bearing G85E did not exhibit less interaction with AHSA1 and Hsp27, neither ubiquitination, after co-administration of C4 and C18. Previous studies have shown that silencing of AHSA1 [28, 30] or Hsp27 [26, 37] markedly stabilizes the folding of CFTR bearing $\triangle F 508$ and blocks protein SUMOylation, respectively. Therefore, co-administration of $\mathrm{C} 4$ and $\mathrm{C} 18$ was inefficient in rectifying the defect of CFTR bearing G85E, leading to protein retention, ubiquitination and degradation, which precluded its trafficking to the cell surface. These findings, as well as functional assays performed with lumacaftor, indicate that: 1) although these mutants interact with a similar proteostasis network, they may bind differently to each of the network's components, resulting in different efficiencies for the same treatment; and 2) each mutant can have a different impact on the overall structure of CFTR, requiring different treatments to rectify their defective proteins.

The rescued CFTR mutant must be a stable protein; otherwise, it will be removed from the cell surface once it is subjected to the system of peripheral quality control proteins [7]. Low-temperature incubation of cells expressing CFTR bearing $\Delta$ F508 can rescue its functional expression at the cell surface [35, 36]; however, the surface-expressed protein is still unstable and is rapidly withdrawn, either by increasing endocytosis of the CFTR [40] or by decreasing its recycling back to the cell surface [41]. Lumacaftor was also inefficient in totally restoring the protein stability of CFTR bearing $\Delta$ F508 [42]. When we co-administered C4 and C18, and subsequently blocked protein synthesis by applying cycloheximide, CFTR bearing E92K, L1077P, or M1101K showed a decline in the amount of protein product during the early temporal course of the experiment, indicating that some of the rescued CFTR was still unstable, and the system of peripheral quality control proteins rapidly removed it. Nevertheless, a substantial amount of rescued CFTR remained stable, being present up to 8 $\mathrm{h}$ after cycloheximide administration. Perhaps our results obtained by co-administering C4 


\section{Cellular Physiology Cell Physiol Biochem 2017;41:2194-2210 \begin{tabular}{c|l} 
DOI: 10.1159/000475578 & $\begin{array}{l}\text { () } 2017 \text { The Author(s). Published by S. Karger AG, Basel } \\
\text { www.karger.com/cpb }\end{array}$
\end{tabular}}

Lopes-Pacheco et al.: Correctors Rescue CFTR Transmembrane-Domain Mutants

and C18 may be enhanced by including a "stabilizer" compound, such as those that promote the interaction between rescued CFTR mutant and $\mathrm{Na}^{+} / \mathrm{H}^{+}$exchanger regulatory factor $1[43$, 44]. However, co-administration of $\mathrm{C} 4$ and $\mathrm{C} 18$ did not rectify the trafficking, function, or stability of CFTR bearing G85E, leaving a continuing need for an effective treatment to rescue this mutant.

Mutations in CFTR cause noteworthy gene and protein variability, leading to different degrees of CF severity. CFTR mutants have been segregated into groups to aid the search for treatments that could rectify mutants with similar defects; however, some of the mutants may present differing structural characteristics or even be unique, responding very differently to the same treatment. In working toward effective approaches, precision medicine is trying to find appropriate pharmacological treatments to overcome the debilitating symptoms in all CF patients [4].

\section{Conclusion}

Our results reveal that co-administration of correctors with different mechanisms of action can restore the trafficking, function, and partial stability of CFTR bearing TMD mutants to the cell surface by mitigating the interactions of the mutated CFTR with the proteostasis network. Finally, these findings indicate that CF patients bearing CFTR mutants E92K, L1077P, or M1101K might benefit from combined treatment with compounds similar to $\mathrm{C} 4$ and C18; however, there is still a significant unmet need for individuals who bear G85E, requiring more studies to identify an appropriate treatment.

\section{Acknowledgments}

The U.S. Cystic Fibrosis Foundation (GUGGIN14XX0), the National Heart, Lung and Blood Institute (R01 HL12267), and the National Council for Scientific and Technological Development (CNPq) from Brazil (granted to M.L.-P.) funded this work. The authors wish to thank W.B. Guggino for help with the manuscript.

\section{Disclosure Statement}

L.C. has a license agreement with the Vertex Corporation for mutant cell lines.

\section{References}

1 Apaja PM, Lukacs GL: Protein homeostasis at the plasma membrane. Physiology (Bethesda) 2014;29:265277.

2 Pankow S, Bamberger C, Calzolari D, Martinez-Bartolome S, Lavallee-Adam M, Balch WE, Yates JR, 3rd: F508 CFTR interactome remodelling promotes rescue of cystic fibrosis. Nature 2015;528:510-516.

-3 Riordan JR, Rommens JM, Kerem B, Alon N, Rozmahel R, Grzelczak Z, Zielenski J, Lok S, Plavsic N, Chou JL: Identification of the cystic fibrosis gene: cloning and characterization of complementary DNA [published erratum appears in Science 1989 Sep 29;245(4925):1437]. Science 1989;245:1066-1073.

4 Lopes-Pacheco M: CFTR modulators: Shedding light on precision medicine for cystic fibrosis. Front Pharmcol 2016;7:275.

5 Serohijos AW, Hegedus T, Aleksandrov AA, He L, Cui L, Dokholyan NV, Riordan JR: Phenylalanine-508 mediates a cytoplasmic-membrane domain contact in the CFTR 3D structure crucial to assembly and channel function. Proc Natl Acad Sci USA 2008;105:3256-3261.

-6 Mendoza JL, Schmidt A, Li Q Nuvaga E, Barrett T, Bridges RJ, Feranchak AP, Brautigam CA, Thomas PJ: Requirements for efficient correction of DeltaF508 CFTR revealed by analyses of evolved sequences. Cell 2012;148:164-174.

7 Okiyoneda T, Barriere H, Bagdany M, Rabeh WM, Du K, Hohfeld J, Young JC, Lukacs GL: Peripheral protein quality control removes unfolded CFTR from the plasma membrane. Science 2010;329:805-810. 


\section{Cellular Physiology Cell Physiol Biochem 2017;41:2194-2210 \begin{tabular}{c|l|l}
\hline DOI: 10.1159/000475578 & () 2017 The Author(s). Published by S. Karger AG, Basel
\end{tabular}

Lopes-Pacheco et al.: Correctors Rescue CFTR Transmembrane-Domain Mutants

8 Sosnay PR, Siklosi KR, Van GF, Kaniecki K, Yu H, Sharma N, Ramalho AS, Amaral MD, Dorfman R, Zielenski J, Masica DL, Karchin R, Millen L, Thomas PJ, Patrinos GP, Corey M, Lewis MH, Rommens JM, Castellani C, Penland CM, Cutting GR: Defining the disease liability of variants in the cystic fibrosis transmembrane conductance regulator gene. Nat Genet 2013;45:1160-1167.

-9 Sosnay PR, Castellani C, Corey M, Dorfman R, Zielenski J, Karchin R, Penland CM, Cutting GR: Evaluation of the disease liability of CFTR variants. Methods Mol Biol 2011;742:355-372.

10 Zhang Z, Chen J: Atomic structure of the cystic fibrosis transmembrane conductance regulator. Cell 2016;167:1586-1597.e1589.

-11 Chen J-M, Cutler C, Jacques C, Bœuf G, Denamur E, Lecointre G, Mercier B, Cramb G, Férec C: A combined analysis of the cystic fibrosis transmembrane conductance regulator: implications for structure and disease models. Mol Biol Evol 2001;18:1771-1788.

-12 Smyth AR, Bell SC, Bojcin S, Bryon M, Duff A, Flume P, Kashirskaya N, Munck A, Ratjen F, Schwarzenberg SJ: European cystic fibrosis society standards of care: best practice guidelines. JCF 2014;13:S23-S42.

13 Van Goor F, Hadida S, Grootenhuis PD, Burton B, Cao D, Neuberger T, Turnbull A, Singh A, Joubran J, Hazlewood A, Zhou J, McCartney J, Arumugam V, Decker C, Yang J, Young C, Olson ER, Wine JJ, Frizzell RA, Ashlock M, Negulescu P: Rescue of CF airway epithelial cell function in vitro by a CFTR potentiator, VX-770. Proc Natl Acad Sci USA 2009;106:18825-18830.

-14 Van GF, Hadida S, Grootenhuis PD, Burton B, Stack JH, Straley KS, Decker CJ, Miller M, McCartney J, Olson ER, Wine JJ, Frizzell RA, Ashlock M, Negulescu PA: Correction of the F508del-CFTR protein processing defect in vitro by the investigational drug VX-809. Proc Natl Acad Sci USA 2011;108:18843-18848.

-15 Clancy JP, Rowe SM, Accurso FJ, Aitken ML, Amin RS, Ashlock MA, Ballmann M, Boyle MP, Bronsveld I, Campbell PW, De BK, Donaldson SH, Dorkin HL, Dunitz JM, Durie PR, Jain M, Leonard A, McCoy KS, Moss RB, Pilewski JM, Rosenbluth DB, Rubenstein RC, Schechter MS, Botfield M, Ordonez CL, Spencer-Green GT, Vernillet L, Wisseh S, Yen K, Konstan MW: Results of a phase IIa study of VX-809, an investigational CFTR corrector compound, in subjects with cystic fibrosis homozygous for the F508del-CFTR mutation. Thorax 2012;67:12-18.

16 Flume PA, Liou TG, Borowitz DS, Li H, Yen K, Ordoñez CL, Geller DE: Ivacaftor in subjects with cystic fibrosis who are homozygous for the F508del-CFTR mutation. Chest J 2012;142:718-724.

-17 Boyle MP, Bell SC, Konstan MW, McColley SA, Rowe SM, Rietschel E, Huang X, Waltz D, Patel NR, Rodman D: A CFTR corrector (lumacaftor) and a CFTR potentiator (ivacaftor) for treatment of patients with cystic fibrosis who have a phe508del CFTR mutation: a phase 2 randomised controlled trial. Lancet Respir Med 2014;2:527-538.

18 Wainwright CE, Elborn JS, Ramsey BW, Marigowda G, Huang X, Cipolli M, Colombo C, Davies JC, De Boeck K, Flume PA, Konstan MW, McColley SA, McCoy K, McKone EF, Munck A, Ratjen F, Rowe SM, Waltz D, Boyle MP: Lumacaftor-Ivacaftor in Patients with Cystic Fibrosis Homozygous for Phe508del CFTR. N Engl J Med DOI:10.1056/NEJMoa1409547.

19 Lopes-Pacheco M, Sabirzhanova I, Rapino D, Morales MM, Guggino WB, Cebotaru L: Correctors Rescue CFTR Mutations in Nucleotide-Binding Domain 1 (NBD1) by Modulating Proteostasis. Chembiochem 2016;17:493-505.

20 Denning GM, Anderson MP, Amara JF, Marshall J, Smith AE, Welsh MJ: Processing of mutant cystic fibrosis transmembrane conductance regulator is temperature-sensitive. Nature 1992;358:761-764.

21 Pedemonte N, Lukacs GL, Du K, Caci E, Zegarra-Moran O, Galietta LJ, Verkman AS: Small-molecule correctors of defective DeltaF508-CFTR cellular processing identified by high-throughput screening. J Clin Invest 2005;115:2564-2571.

-22 Cheng SH, Gregory RJ, Marshall J, Paul S, Souza DW, White GA, O'Riordan CR, Smith AE: Defective intracellular transport and processing of CFTR is the molecular basis of most of cystic fibrosis. Cell 1990;63:827-834.

23 Okiyoneda T, Veit G, Dekkers JF, Bagdany M, Soya N, Xu H, Roldan A, Verkman AS, Kurth M, Simon A, Hegedus T, Beekman JM, Lukacs GL: Mechanism-based corrector combination restores DeltaF508-CFTR folding and function. Nat Chem Biol 2013;9:444-454.

-24 Rapino D, Sabirzhanova I, Lopes-Pacheco M, Grover R, Guggino WB, Cebotaru L: Rescue of NBD2 mutants N1303K and S1235R of CFTR by small-molecule correctors and transcomplementation. PLoS One 2015;10:e0119796.

-25 Van GF, Straley KS, Cao D, Gonzalez J, Hadida S, Hazlewood A, Joubran J, Knapp T, Makings LR, Miller M, Neuberger T, Olson E, Panchenko V, Rader J, Singh A, Stack JH, Tung R, Grootenhuis PD, Negulescu P: 


\section{Cellular Physiology Cell Physiol Biochem 2017;41:2194-2210 \begin{tabular}{c|l|l}
\hline DOI: 10.1159/000475578 & (c) 2017 The Author(s). Published by S. Karger AG, Basel
\end{tabular} and Biochemistry}

Lopes-Pacheco et al.: Correctors Rescue CFTR Transmembrane-Domain Mutants

Rescue of DeltaF508-CFTR trafficking and gating in human cystic fibrosis airway primary cultures by small molecules. AmJ Physiol Lung Cell Mol Physiol 2006;290:L1117-L1130.

-26 Ahner A, Gong X, Schmidt BZ, Peters KW, Rabeh WM, Thibodeau PH, Lukacs GL, Frizzell RA: Small heat shock proteins target mutant cystic fibrosis transmembrane conductance regulator for degradation via a small ubiquitin-like modifier-dependent pathway. Mol Biol Cell 2013;24:74-84.

-27 Coppinger JA, Hutt DM, Razvi A, Koulov AV, Pankow S, Yates JR, III, Balch WE: A chaperone trap contributes to the onset of cystic fibrosis. PLoSOne 2012;7:e37682.

28 Wang X, Venable J, LaPointe P, Hutt DM, Koulov AV, Coppinger J, Gurkan C, Kellner W, Matteson J, Plutner H, Riordan JR, Kelly JW, Yates JR, III, Balch WE: Hsp90 cochaperone Aha1 downregulation rescues misfolding of CFTR in cystic fibrosis. Cell 2006;127:803-815.

29 Koulov AV, LaPointe P, Lu B, Razvi A, Coppinger J, Dong MQ Matteson J, Laister R, Arrowsmith C, Yates JR, III, Balch WE: Biological and structural basis for Aha1 regulation of Hsp90 ATPase activity in maintaining proteostasis in the human disease cystic fibrosis. Mol Biol Cell 2010;21:871-884.

- 30 Boyault C, Gilquin B, Zhang Y, Rybin V, Garman E, Meyer-Klaucke W, Matthias P, Muller CW, Khochbin S: HDAC6-p97/VCP controlled polyubiquitin chain turnover. EMBO J 2006;25:3357-3366.

-31 Kawaguchi Y, Kovacs JJ, McLaurin A, Vance JM, Ito A, Yao TP: The deacetylase HDAC6 regulates aggresome formation and cell viability in response to misfolded protein stress. Cell 2003;115:727-738.

32 Vij N, Fang S, Zeitlin PL: Selective inhibition of endoplasmic reticulum-associated degradation rescues DeltaF508-cystic fibrosis transmembrane regulator and suppresses interleukin-8 levels: therapeutic implications. J Biol Chem 2006;281:17369-17378.

-33 Hutt DM, Herman D, Rodrigues AP, Noel S, Pilewski JM, Matteson J, Hoch B, Kellner W, Kelly JW, Schmidt A, Thomas PJ, Matsumura Y, Skach WR, Gentzsch M, Riordan JR, Sorscher EJ, Okiyoneda T, Yates JR, III, Lukacs GL, Frizzell RA, Manning G, Gottesfeld JM, Balch WE: Reduced histone deacetylase 7 activity restores function to misfolded CFTR in cystic fibrosis. Nat Chem Biol 2010;6:25-33.

-34 Jensen TJ, Loo MA, Pind S, Williams DB, Goldberg AL, Riordan JR: Multiple proteolytic systems, including the proteasome, contribute to CFTR processing. Cell 1995;83:129-135.

35 Lukacs GL, Chang XB, Bear C, Kartner N, Mohamed A, Riordan JR, Grinstein S: The delta F508 mutation decreases the stability of cystic fibrosis transmembrane conductance regulator in the plasma membrane. Determination of functional half-lives on transfected cells. J Biol Chem 1993;268:21592-21598.

-36 Sharma M, Benharouga M, Hu W, Lukacs GL: Conformational and temperature-sensitive stability defects of the delta F508 cystic fibrosis transmembrane conductance regulator in post-endoplasmic reticulum compartments. J Biol Chem 2001;276:8942-8950.

-37 Lopes-Pacheco M, Boinot C, Sabirzhanova I, Morales MM, Guggino WB, Cebotaru L: Combination of Correctors Rescue $\Delta$ F508-CFTR by Reducing Its Association with Hsp40 and Hsp27. J Biol Chem 2015;290:25636-25645.

-38 Patrick AE, Karamyshev AL, Millen L, Thomas PJ: Alteration of CFTR transmembrane span integration by disease-causing mutations. Mol Biol Cell 2011;22:4461-4471.

-39 Kakoi S, Yorimitsu T, Sato K: COPII machinery cooperates with ER-localized Hsp40 to sequester misfolded membrane proteins into ER-associated compartments. Mol Biol Cell 2013;24:633-642.

-40 Swiatecka-Urban A, Brown A, Moreau-Marquis S, Renuka J, Coutermarsh B, Barnaby R, Karlson KH, Flotte TR, Fukuda M, Langford GM: The short apical membrane half-life of rescued $\Delta$ F508-cystic fibrosis transmembrane conductance regulator (CFTR) results from accelerated endocytosis of $\triangle$ F508-CFTR in polarized human airway epithelial cells. J Biol Chem 2005;280:36762-36772.

-41 Sharma M, Pampinella F, Nemes C, Benharouga M, So J, Du K, Bache KG, Papsin B, Zerangue N, Stenmark H, Lukacs GL: Misfolding diverts CFTR from recycling to degradation: quality control at early endosomes. J Cell Biol 2004;164:923-933.

42 He L, Kota P, Aleksandrov AA, Cui L, Jensen T, Dokholyan NV, Riordan JR: Correctors of DeltaF508 CFTR restore global conformational maturation without thermally stabilizing the mutant protein. FASEB J 2013;27:536-545.

43 Loureiro CA, Matos AM, Dias-Alves A, Pereira JF, Uliyakina I, Barros P, Amaral MD, Matos P: A molecular switch in the scaffold NHERF1 enables misfolded CFTR to evade the peripheral quality control checkpoint. Sci Signal 2015;8:ra48.

44 Lobo MJ, Amaral MD, Zaccolo M, Farinha CM: EPAC1 activation by cAMP stabilizes CFTR at the membrane by promoting its interaction with NHERF1. J Cell Sci 2016;129:2599-2612. 